\title{
Simplified Nail Clipping Test for Diagnosis of Cystic Fibrosis
}

\author{
M. ANTONELLI*, G. BALLATI, and L. ANNIBALDI \\ From First and Second Paediatric Clinics, University of Rome, Italy
}

It has been recently observed that sodium and potassium concentrations in the nails of cases of cystic fibrosis are higher than in those of controls (Kopito and Shwachman, 1964; Kopito et al., 1965). The original method described is complicated and time consuming. The purpose of this study is to present the results obtained with a simpler procedure for the estimation of sodium and potassium in nails, and to evaluate the method for the diagnosis of cystic fibrosis.

\section{Material and Methods}

Nail clippings from fingers and toes were obtained from 121 subjects grouped as follows: 22 patients with cystic fibrosis (CF) aged between 2 months and 9 years; 22 healthy children of corresponding ages; 30 parents of patients with CF; 17 healthy sibs of patients with $\mathrm{CF}$, aged between 13 months and 22 years; and 30 healthy adults of comparable ages to the parental group.

Specimens were obtained at random without any special instruction to the donor. Visible dirt was scraped off the surface before the nail clippings were weighed and placed in hermetically sealed plastic vials. The minimal quantity of nails necessary for analysis was $20 \mathrm{mg}$. The nail clippings were transferred into Pyrex tubes and placed in an oven at $600{ }^{\circ} \mathrm{C}$. for 2 hours and ashed, a white uniform colour indicating that ashing was complete. Ion-free water and lithium were added to the ash in the following proportion; nails $100 \mathrm{mg}$.: water $47.5 \mathrm{ml}$.: lithium (5000 p.p.m.) $2.5 \mathrm{ml}$. Sodium and potassium were estimated by flame photometer and calculated as $\mathrm{mEq} / \mathrm{kg}$. nails.

\section{Results}

No significant difference was observed between the electrolyte levels of nails of the fingers and toes in 5 fibrocystics, the mean sodium value being $173 \mathrm{mEq} / \mathrm{kg}$. in finger-nails and $180 \mathrm{mEq} / \mathrm{kg}$. in toe-nails, and potassium mean values $9 \mathrm{mEq} / \mathrm{kg}$. in finger-nails and $10.6 \mathrm{mEq} / \mathrm{kg}$. in toe-nails.

Received September 12, 1968.

* Present address: Clinica Pediatrica dell'Università di Roma, Viale Regina Elena 324, 00100 Roma, Italy.
The distribution of sodium concentrations in nail clippings from the five groups of subjects tested (Fig.) showed generally high values in the 22 patients with $C F$, with a wide distribution between 64 and $420 \mathrm{mEq} / \mathrm{kg}$. 4 patients had values between 60 and $80 \mathrm{mEq} / \mathrm{kg}$. which we regard as a borderline zone, but in all 4 the clinical picture was typical of $\mathrm{CF}$, and the sodium sweat values were higher than $100 \mathrm{mEq} / 1$.

Of the 22 healthy children, sodium values were below $60 \mathrm{mEq} / \mathrm{kg}$. in all except one.

The sodium values for 30 parents of CF patients showed a distribution similar to but wider than those found in 30 adult controls. By contrast, the distribution of sodium values for the 17 healthy sibs ranged from normal levels in 8 subjects to values well in the typical CF range in 6 subjects, with 3 subjects falling in the borderline zone. Sodium values of healthy sibs were the mean of three subsequent determinations, and sweat test for the same subjects gave normal sodium concentrations $(<50 \mathrm{mEq} / \mathrm{l}$.).

Table I indicates the values of sodium from nail clippings of the 5 groups tested at the 10th, 50th, and 90th centiles. The differences are highly significant $(p<0.01)$ between patients and healthy children; patients and their sibs; patients and their parents; sibs of patients and healthy children; sibs and their parents (Table II). The difference between healthy children and healthy adults was not significant.

Potassium concentrations, though often higher in the nails of CF patients did not differ significantly among the groups tested.

\section{Discussion}

The earlier method, which involved washing the nail clippings (Kopito and Shwachman, 1964; Kopito et al., 1965) before analysis, was aimed at avoiding contamination with sweat before or during collection of specimens. However, we 
TABLE I

Centile Distribution of Sodium Concentration in Finger Nails

\begin{tabular}{|c|c|c|c|c|c|c|}
\hline \multirow[t]{2}{*}{ Subjects } & \multirow{2}{*}{ No. } & \multicolumn{2}{|c|}{ Age (yr.) } & \multicolumn{3}{|c|}{$\begin{array}{c}\text { Sodium }(\mathrm{mEq} / \mathrm{kg} .) \\
\text { Centiles }\end{array}$} \\
\hline & & Mean & Range & 10th & 50th & 90th \\
\hline $\begin{array}{l}\text { Patients with CF } \\
\text { Healthy children } \\
\text { Sibs of patients }\end{array}$ & $\begin{array}{l}22 \\
22\end{array}$ & $\begin{array}{l}3.6 \\
3.6\end{array}$ & $\begin{array}{l}0 \cdot 2-9 \\
0 \cdot 2-9\end{array}$ & $\begin{array}{l}70 \\
14\end{array}$ & $\begin{array}{r}170 \\
21\end{array}$ & $\begin{array}{r}340 \\
51\end{array}$ \\
\hline $\begin{array}{l}\text { with CF } \\
\text { Parents of } \\
\text { patients with } \\
\text { CF }\end{array}$ & 17 & $7 \cdot 2$ & $1 \cdot 1-22$ & 36 & 64 & 130 \\
\hline Healthy adults . & 30 & 30 & $\begin{array}{l}22-31 \\
22-50\end{array}$ & 10 & $\begin{array}{l}23 \\
17\end{array}$ & 39 \\
\hline
\end{tabular}

have found that when nails are contaminated with sweat it is sufficient to dry them with blotting paper before collection; if this precaution is taken, we have observed no significant difference between sodium and potassium concentrations of washed and unwashed clippings (Antonelli et al., 1968).

The concentrations of sodium in nail clippings using our method were similar to those obtained by Kopito et al. with their procedure in similar groups of subjects. Potassium levels were somewhat lower in our study, but this difference does not affect the diagnostic value of a method based on sodium estimation.

As there is no significant difference between the finger-nail and the toe-nail composition, it is possible to use the method in newborn babies and small infants, using nail clippings of one or more collections from fingers and toes. In 20 of 23 newborns tested it was possible to accumulate

TABLE II

Statistical Significance of Differences Between Values of Groups Studied

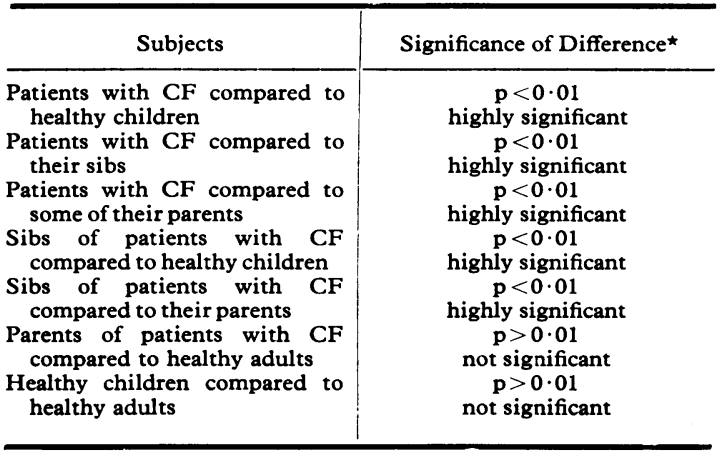

৯ Wilcoxon Rank sum test (Wilcoxon and Wilcox, 1964). at least $20 \mathrm{mg}$. of nails from fingers and toes taken in three subsequent cuttings at 10-day intervals.

The advantage of our method is that sodium is estimated in the whole sample, whereas the original procedure required the determination of electrolytes both in the wash and in the nail specimen.

The fact that some of the healthy sibs of patients with CF had high sodium concentrations in their nails is of interest, and raises the question of whether these subjects were heterozygotes for the gene of CF. The healthy sibs all had sodium sweat values below $50 \mathrm{mEq} / \mathrm{l}$. This hypothesis apparently conflicts with the fact that sodium values found in nails of parents (presumed heterozygotes) were not significantly different from those in normal adults. The difference between sibs (high values)

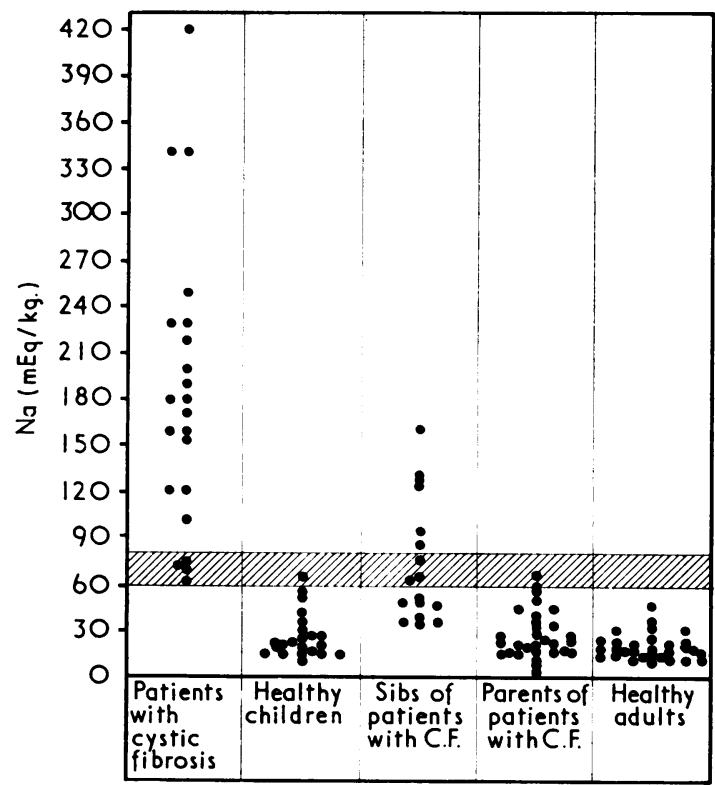

FIG.-Concentrations of sodium ( $m E q / k g$.) in nails of groups tested.

and parents (normal values) may, however, be due to the observed lowering of electrolyte content in nails from childhood to adulthood (Antonelli et al., 1968; Bock et al., 1967), and to the decrease in electrolyte composition of the body with increasing age. At the moment there are not sufficient data to establish the value of the nail clipping test for detecting heterozygotes among children.

This method may prove useful in cases in which a sweat test cannot be performed or gives boderline 
values, or when a patient is far from a diagnostic centre.

\section{Summary}

A simplified procedure for determining sodium and potassium levels in nail clippings is described; this test was carried out in 121 subjects. Patients with cystic fibrosis showed much higher sodium values than controls. Some healthy sibs had values well in the range of cystic fibrosis, raising the possibility that this method may allow detection of heterozygote carriers of cystic fibrosis.

\section{REFERENCES}

Antonelli, M., Giardini, O., Sartori, L., and Carratù, A. (1968). Study of sodium and potassium values in the nails of healthy subjects at different ages. In the press.
Bock, H., Koch, E., Stephan, U., Windorfer, A., Sitzmann, F. C., and Grosse, H. (1967). Investigation of electrolyte concentrations in the nails of cystic fibrosis patients and controls. Mod. Probl. Pädiat., 10, 279.

Kopito, L., Mahmoodian, A., Townley, R. R. W., Khaw, K. T., and Shwachman, H. (1965). Studies in cystic fibrosis. Analysis of nail clippings for sodium and potassium. New Engl. F. Med., 272, 504.

, and Shwachman, H. (1964). Spectroscopic analysis of tissues from patients with cystic fibrosis and controls. Nature (Lond.), 202, 501.

Wilcoxon, F., and Wilcox, R. A. (1964). Some rapid approximate statistical procedure. Lederle Lab., Pearl Review, N.Y., p. 7.

Correspondence to Dr. M. Antonelli, Clinica Pediatrica dell' Università di Roma, Viale Regina Elena 324, 00100 Roma, Italy. 